\title{
Evolution of Lateritic Soils Geotechnical Parameters During a Multi-Cyclic OPM Compaction and Correlation with Road Traffic
}

\author{
Meissa Fall ${ }^{1}$, Déthiè Sarr ${ }^{1}$, Makhaly Ba ${ }^{1}$, Etienne Berbinau $^{2}$, Jean-Louis Borel $^{2}$, \\ Mapathé Ndiaye ${ }^{1}$, Cheikh H. Kane ${ }^{1}$ \\ ${ }^{1}$ Laboratoire de Mécanique et Modélisation, UFR Sciences de l'Ingénieur, University of Thies, Thies, Senegal \\ ${ }^{2}$ RAZEL sa, Christ de Sarclay, 3 rue René razel, Orsay cedex, Orsay, France \\ E-mail: meissa.fall@univ-thies.sn
}

Received August 8, 2011; revised September 13, 2011; accepted September 22, 2011

\begin{abstract}
Gravel lateritic soils are intensively used in road geotechnical engineering. This material is largely representative of engineering soil all around the tropical African Countries [1,2]. Gravel lateritic soils from parts of Burkina Faso and Senegal (West Africa) are used to determine the evolution of the geotechnical parameters from one to ten cycles of modified Proctor compaction. This test procedure is non-common for geotechnical purposes and it was found suitable and finally adopted to describe how these problematic soils behave when submitted to a multi-cyclic set of Modified Proctor compactions (OPM) [3,4]. On another hand, we propose a correlation between the traffic and the cycles of compaction considered as the repeated load. From that, this work shows the generation of active fine particles, the decrease of the CBR index and also the mechanical characteristics (mainly the Young Modulus, E) that contribute at least to the main deformation of the road structure.
\end{abstract}

Keywords: Optimum Moisture Content (OPM), Multi-Cyclic Compaction, CBR, AASHTO, Fines, Lateritic Soil, Road Structure

\section{Introduction}

This paper is primarily intended to demonstrate that under unpredicted traffic and repeated loading, properties of gravel lateritic soils used as pavement layer can significantly change. According to [5-10], gravel lateritic soils are very sensitive to an exceptional variation of stresses under which they are subjected in a pavement structural fill. Thus, it is expected that most of the physical and mechanical properties of gravel lateritic soils evolves during the design life.

It is then important to find an adequate method of testing that can deal with such behavior already known in the literature. It is then necessary to perform usual characterization tests on these kinds of materials by studying the evolution of their main properties under traffic such as gradation, plasticity, CBR (Californian Bearing ration), Los Angeles loss, Shear strength (UCT), etc.

To do this, tests are conducted so that they can simulate multi-cyclic axial loading generated by traffic loads. The first cycle of OPM compaction (cycle 1) corresponds to the specifications that are led to the initial design of pavement:

- Compaction at the Optimum Modified Proctor (OPM) and determination of the initial CBR value of the material that will have to support traffic.

- Determination during the same initial state of all physical and mechanical characteristics of materials, as reference values such as gradation, Atterberg limits, CBR, Los Angeles loss, Shear strength as Unconfined Compression Test characteristics (UCT), etc.

- And finally, perform multi-cyclic compaction procedure to determine soil characteristics at each cycle of compaction.

\section{Test Procedure and Material Properties}

After complete characterization of a gravel lateritic specimen from Burkina Faso (between Boromo and Bobo Dioulasso mainly used for the design of this West African 
International Road) and Senegal (in the western part of the country, as Yenne and Thiès), (sieve and hydrometer analysis, Atterberg limits, methylene blue, etc.), soils are compacted and subjected to mechanical tests at the Optimum Modified Proctor (OPM). Theses mechanical tests are essentially CBR tests, unconfined compression test and resistance to degradation by abrasion and impact in the
Los Angeles machine. After the first cycle, the remaining material is used to perform exactly the same tests during the subsequent cycles $\left(2^{\text {nd }}, 3^{\text {rd }}, \ldots, 10^{\text {th }}\right.$ cycles) (Table 1). The purpose of these tests is to compare the evolution of main properties (particle size distribution, CBR, Young modulus, etc.) with repeated cycles of compaction. Tables 2(a) and (b) below summarize the overall results:

Table 1. Values of material properties at cycle 0 (raw material), (The main Lateritic Soils used in this paper are sampled from Burkina Faso between Boromo and Bobo Dioulasso).

\begin{tabular}{ccc}
\hline & (fines) $\mathbf{\%}<\mathbf{8 0 ~ \mathbf { ~ }}$ & PI (\%) \\
\hline Pk 247 & 14 & 15 \\
Pk 272 + 600 & 16 & 17 \\
Pk 284 & 15 & 10 \\
Pk 288 & 18 & 15 \\
Pk 342 & 20 & 12 \\
\hline
\end{tabular}

Table 2a. Summary of the test results depending on the soil provenance and the cycles of compaction.

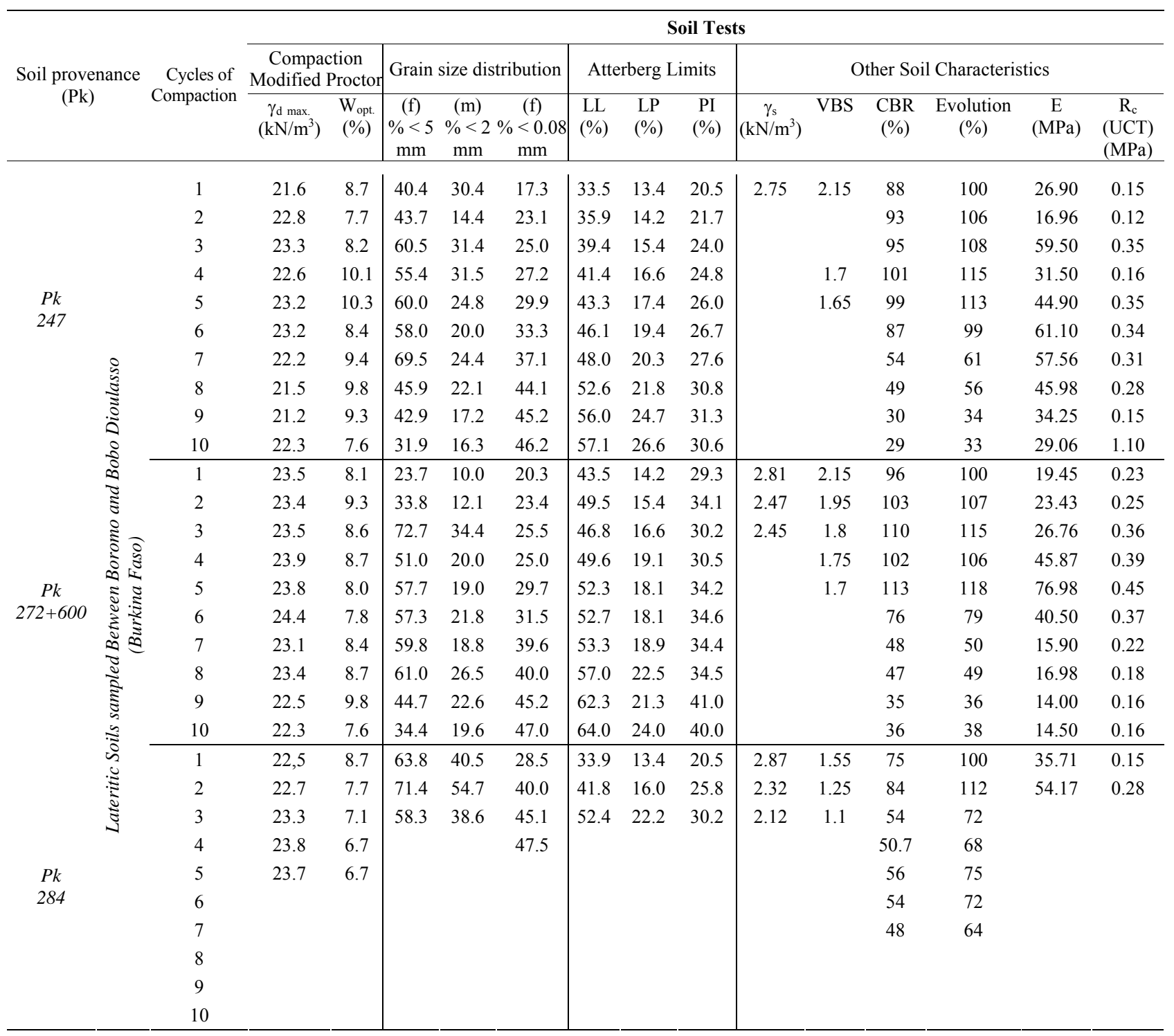


Table $2 \mathrm{~b}$. Summary of the test results depending on the soil provenance and the cycles of compaction. * (Empty cells indicate insufficient quantity of materials for further testing. Multi-cyclic compaction uses a large amount of material per cycle. In this case, several samples were compacted at the same water content in order to provide enough amount of material for each cycle).

\begin{tabular}{|c|c|c|c|c|c|c|c|c|c|c|c|c|c|c|c|c|}
\hline \multirow{3}{*}{ Soil 1} & & \multirow{3}{*}{$\begin{array}{l}\text { Cycles of } \\
\text { Compaction }\end{array}$} & \multicolumn{14}{|c|}{ Soil Tests } \\
\hline & venance & & \multicolumn{2}{|c|}{$\begin{array}{c}\text { Compaction } \\
\text { Modified Proctor }\end{array}$} & \multicolumn{3}{|c|}{ Grain size distribution } & \multicolumn{3}{|c|}{ Atterberg Limits } & \multicolumn{6}{|c|}{ Other Soil Characteristics } \\
\hline & & & $\begin{array}{c}\gamma_{\mathrm{d} \text { max }} \\
\left(\mathrm{kN} / \mathrm{m}^{3}\right)\end{array}$ & $\begin{array}{l}\mathrm{W}_{\text {opt. }} \\
(\%)\end{array}$ & $\begin{array}{c}\text { (f) } \\
\%<5 \\
\mathrm{~mm}\end{array}$ & $\begin{array}{c}(\mathrm{m}) \\
\%<2 \\
\mathrm{~mm}\end{array}$ & $\begin{array}{c}(\mathrm{f}) \\
\%<0.08 \\
\mathrm{~mm}\end{array}$ & $\begin{array}{l}\text { LL } \\
(\%)\end{array}$ & $\begin{array}{l}\text { LP } \\
(\%)\end{array}$ & $\begin{array}{l}\text { PI } \\
(\%)\end{array}$ & $\begin{array}{c}\gamma_{\mathrm{s}} \\
\left(\mathrm{kN} / \mathrm{m}^{3}\right)\end{array}$ & VBS & $\begin{array}{c}\text { CBR } \\
(\%)\end{array}$ & $\begin{array}{c}\text { Evolution } \\
(\%)\end{array}$ & $\begin{array}{c}\mathrm{E} \\
(\mathrm{MPa})\end{array}$ & $\begin{array}{c}\mathrm{R}_{\mathrm{c}}(\mathrm{UCT}) \\
(\mathrm{MPa})\end{array}$ \\
\hline \multirow{10}{*}{$\begin{array}{c}P k \\
288\end{array}$} & \multirow{20}{*}{ 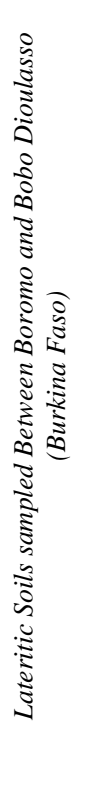 } & 1 & 23.0 & 7.1 & 58.4 & 15.9 & 26.2 & 34.7 & 11.8 & 22.9 & 2.73 & 2.25 & 81 & 100 & 15.60 & 0.18 \\
\hline & & 2 & 22.6 & 9.3 & 43.4 & 19.7 & 30.3 & 42.8 & 16.4 & 26.4 & 2.5 & 1.9 & & & 23.15 & 0.20 \\
\hline & & 3 & 23.6 & 8.1 & 44.5 & 22.1 & 31.0 & 43.8 & 17.4 & 26.5 & 2.39 & 1.8 & & & 15.60 & 0.18 \\
\hline & & 4 & 24.2 & 7.6 & 44.0 & 21.0 & & 47.4 & 18.1 & 29.3 & & 1.75 & & & 32.30 & 0.38 \\
\hline & & 5 & 24.0 & 8.6 & 60.1 & 25.4 & & 49.6 & 19.4 & 30.2 & & & & & 32.40 & 0.32 \\
\hline & & 6 & 22.5 & 11.8 & 57.0 & 19.8 & & & & & & & & & 28.70 & 0.32 \\
\hline & & 7 & 22.2 & 9.4 & 58.9 & 18.1 & & & & & & & & & 25.32 & 0.35 \\
\hline & & 8 & 21.5 & 9.8 & 44.7 & 20.4 & & & & & & & & & 20.50 & 0.25 \\
\hline & & 9 & 21.2 & 9.3 & 39.7 & 14.6 & & & & & & & & & 22.30 & 0.11 \\
\hline & & 10 & 20.4 & 9.3 & 33.6 & 18.6 & & & & & & & & & 18.15 & 0.12 \\
\hline \multirow{10}{*}{$\begin{array}{c}P k \\
342\end{array}$} & & 1 & 23.4 & 7.3 & 43.7 & 33.7 & 28.2 & 31.3 & 15.5 & 15.8 & 2.87 & 1 & 84 & 100 & 33.33 & 0.11 \\
\hline & & 2 & 23.4 & 7.4 & 50.7 & 39.7 & 35.3 & 47.4 & 19.1 & 28.3 & 2.71 & 1.25 & 90 & 107 & 25.00 & 0.11 \\
\hline & & 3 & 23.3 & 5.5 & 50.4 & 38.8 & & 61.8 & 21.1 & 40.6 & 2.33 & 0.9 & 97 & 115 & & \\
\hline & & 4 & 23.7 & 5.7 & & & & & & & & & 105 & 125 & & \\
\hline & & 5 & 23.6 & 6.8 & & & & & & & & & 95 & 113 & & \\
\hline & & 6 & & & & & & & & & & & & & & \\
\hline & & 7 & & & & & & & & & & & & & & \\
\hline & & 8 & & & & & & & & & & & & & & \\
\hline & & 9 & & & & & & & & & & & & & & \\
\hline & & 10 & & & & & & & & & & & & & & \\
\hline
\end{tabular}

\section{Interpretation of Results}

\subsection{Generation of Fine particles and Changing in Characteristics of Consistency}

As shown by figures below, the transition between first to $10^{\text {th }}$ cycles contributes to a strong generation of fine particles, as well as a gradual increase of plasticity (Figure 1). The amount of fines particles $(\%<80 \mu \mathrm{m})$ increases from $17 \%$ (which is the limit generally accepted for such materials) for the first cycle and reaches $46 \%$ for the $10^{\text {th }}$ cycle. From the first to the $10^{\text {th }}$ cycle, plasticity of materials also changes from $21 \%$ to $31 \%$ for the sample of $\mathrm{Pk} 247$ and from $29 \%$ to $40 \%$ for the sample of Pk $272+600$.

The Figure 2 gives the results of Los Angeles tests performed on gravel lateritic soils samples. The test was conducted in a particular procedure that is "unconventional". In the case of the strict application of the standard, the test is performed in the fraction 10/14 with a mass of test sample of $5 \mathrm{~kg}$. For our purposes, we took care to fill the hollow steel cylinder with the total fraction of the material without any selection. This procedure allows testing the total mass of the initial material without any selection and therefore allows completing Figure 3 showing the generation of fine particles and changes in plasticity. Since the test measures the resistance to degradation by abrasion and impact of the material in a rotating steel drum containing a specified number of steel balls, results show a strong increase of percent loss by abrasion and impact as the number of cycle increases. In this sense, both coarse and fine aggregates fragment extensively during the test. This further demonstrates the problematic behavior of all gravel lateritic soils related in the literature [10].

\subsection{Comparison with the Specifications in the Western African Area (West African Standards-WAS)}

From Figure 3 we can remark that, at the end of compaction cycles, materials tested are outside of specifications for the plasticity index and the amount of fine particles $(<80 \mu \mathrm{m})$ as required by specifications. 


\section{PK 272+600}

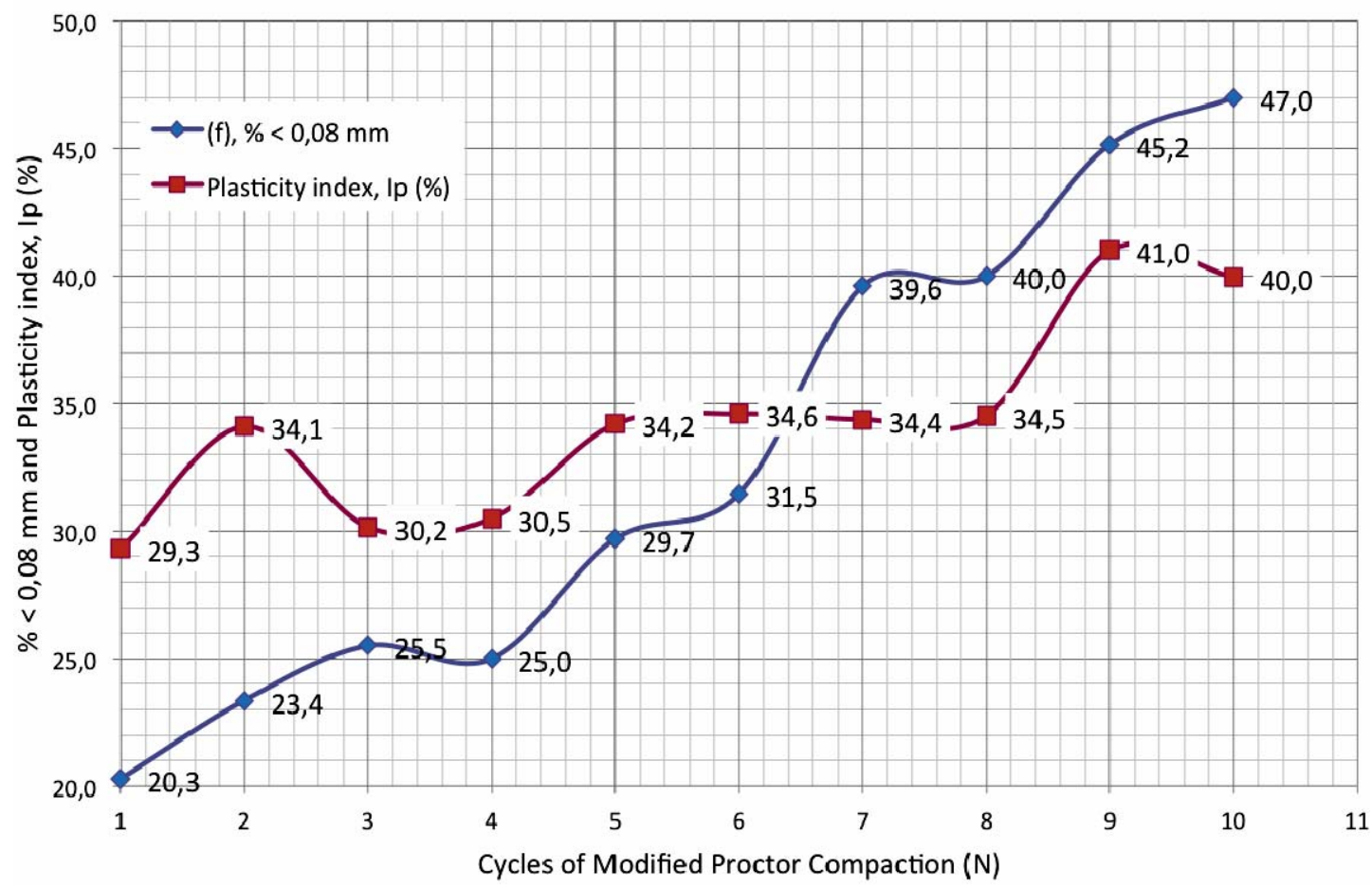

Figure 1. Evolution des fines $(\%<80 \mathrm{~m})$ et de la plasti-cité $(\mathrm{PI})(\mathrm{Pk} 272+600)$.

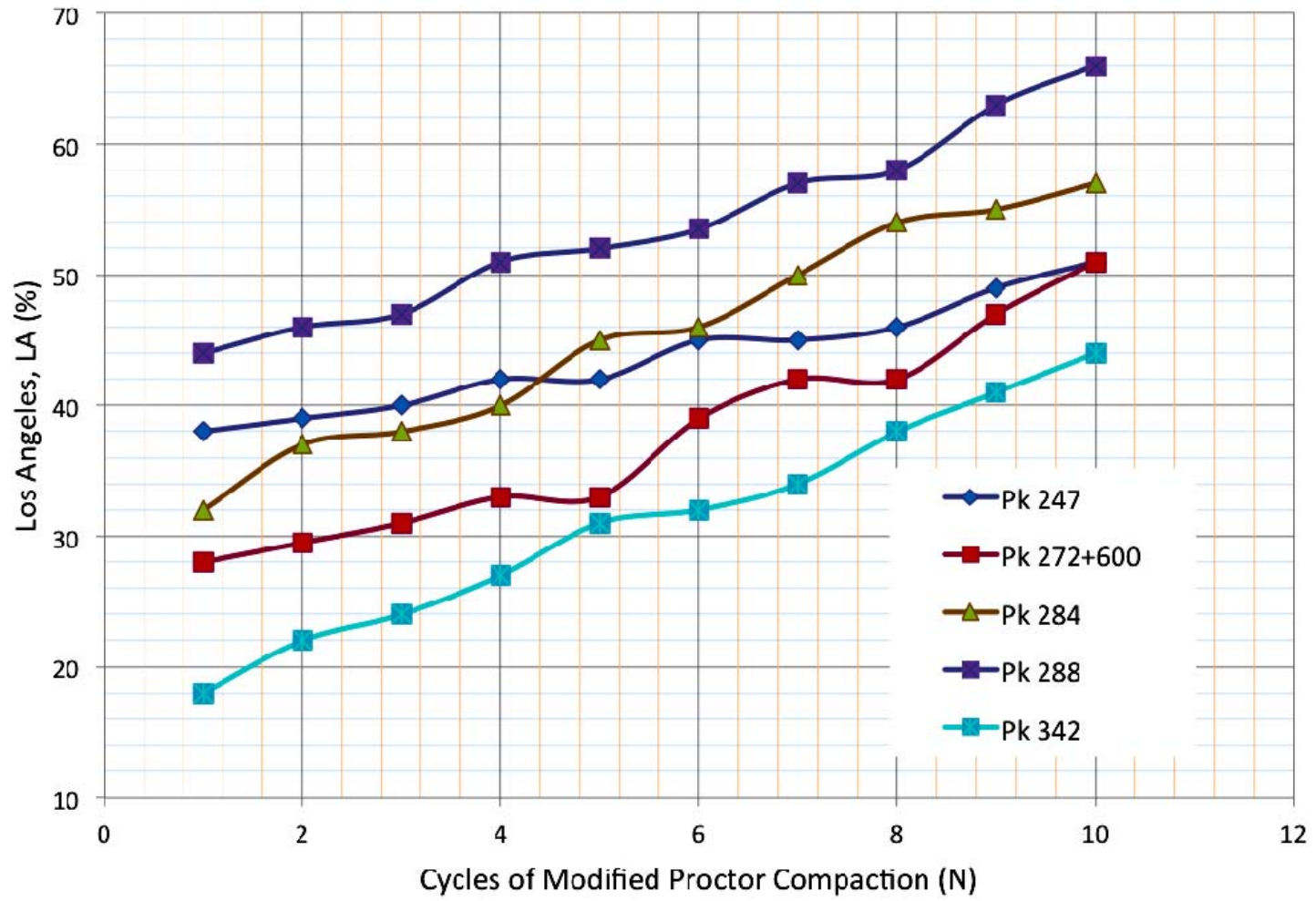

Figure 2. Evolution of percentage loss by abrasion. 


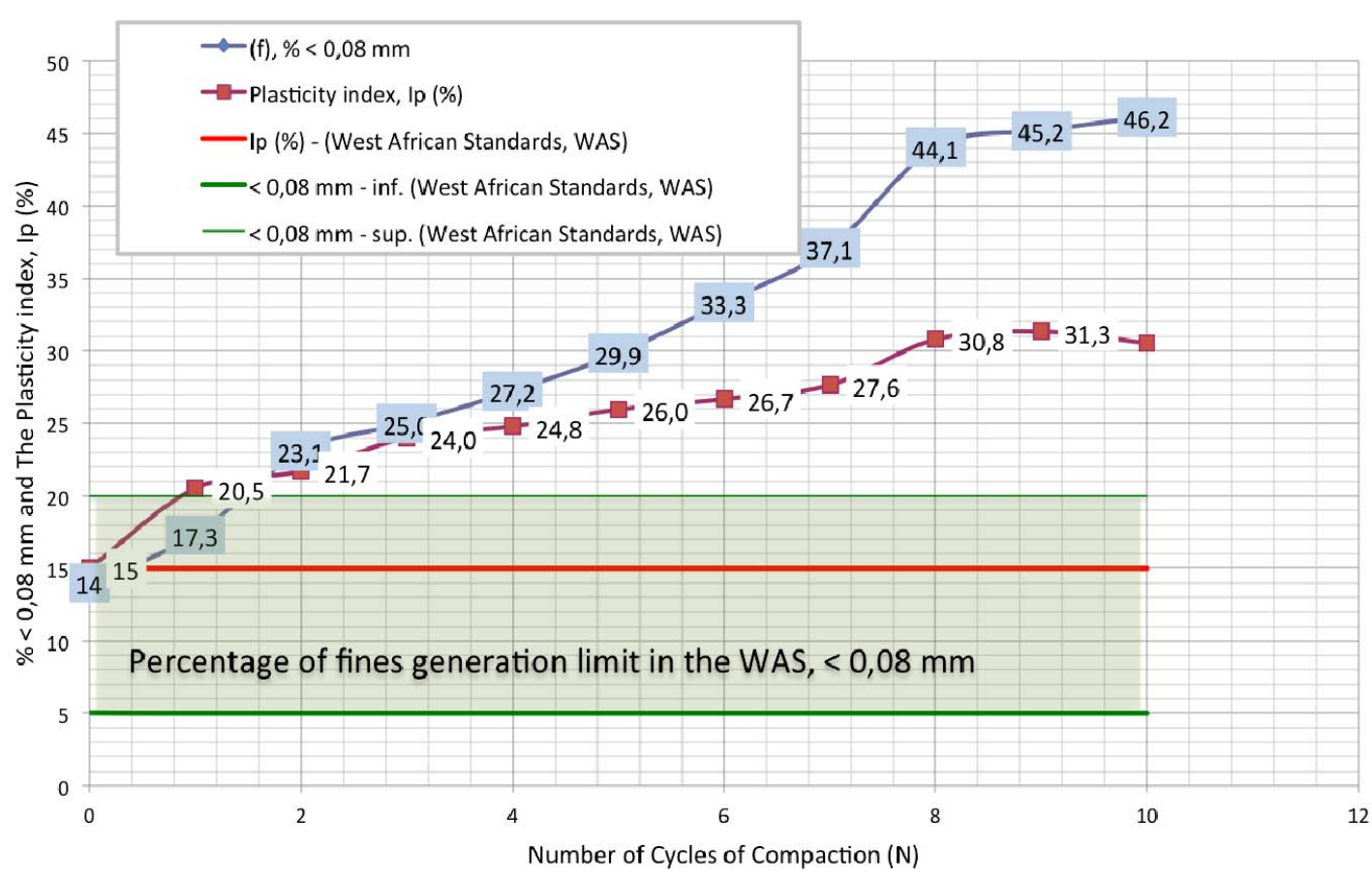

Figure 3. Comparison between results $(<0.08 \mathrm{~mm}$ et $\mathrm{PI}(\%))$ and specification of the WAS.

Figure 4 shows the variation of CBR values with the cycles of modified Proctor compaction. Table $\mathbf{3}$ below reminds technical recommendations contained in current textbooks approved by the CEBTP, the BCEOM and the LCPC [11] for the use of gravel lateritic soils as base courses and in the case of a $T_{1}$ to $T_{2}$ traffic level:

\subsection{Evolution of the CBR Values}

CBR is analyzed in several ways (Figure 7):

- In gross value, the CBR is changing slightly for all materials up to the 5th cycle. This trend towards material stiffening is well known. Fall et al. [10] underlines that behavior and attributes it to the fact that the soil is becoming denser during the first cy cles. It gradually changes from a loose state to a dense state. Air void between coarse grains tends to be reduced and filled by fine particles generated by the breaks of the material.
- The trend to the fifth cycle is to increase the CBR, which passes from a reference value of $100 \%$ and goes up to $118 \%$ or $113 \%$. In gross value, the CBR increases from $88 \%$ to $101 \%$ and from 96 to $113 \%$.

- After the fifth cycle, the CBR begins to drop strongly and eventually reaches extremely low values such as $29 \%$ and $36 \%$ (sometimes approaching $67 \%$ ) for the gravel lateritic base course.

Trends explained in figures $\mathbf{5}$ and $\mathbf{6}$ are much clearer in Figure 7 where the material stiffening is more perceptible. The stiffness increases from 0 to 5 cycles and then decreases considerably after the fifth cycle.

Note:

Whatever the type of correlations made on the basis of CBR, we should have, in all cases, moduli that drop significantly when the number of cycles increases. In these cases, the design of pavement base courses should lead to a significant increase in thicknesses.

Table 3. Specification for a base layer for traffic $T_{1}-T_{2}$.

\begin{tabular}{lccc}
\hline & CBR $_{\text {4d imbibition }}$ at 95\% OPM & PI (\%) & \% inf. at $80 \boldsymbol{\mu m ~ ( \% ) ~}$ \\
\hline CEBTP & 80 & $<15$ & 4 à 20 \\
CEBTP-LCPC & 80 & $<15$ & $<15$ \\
CEBTP-BCEOM & 80 & $<15$ & $<15$ \\
\hline
\end{tabular}


PK 247

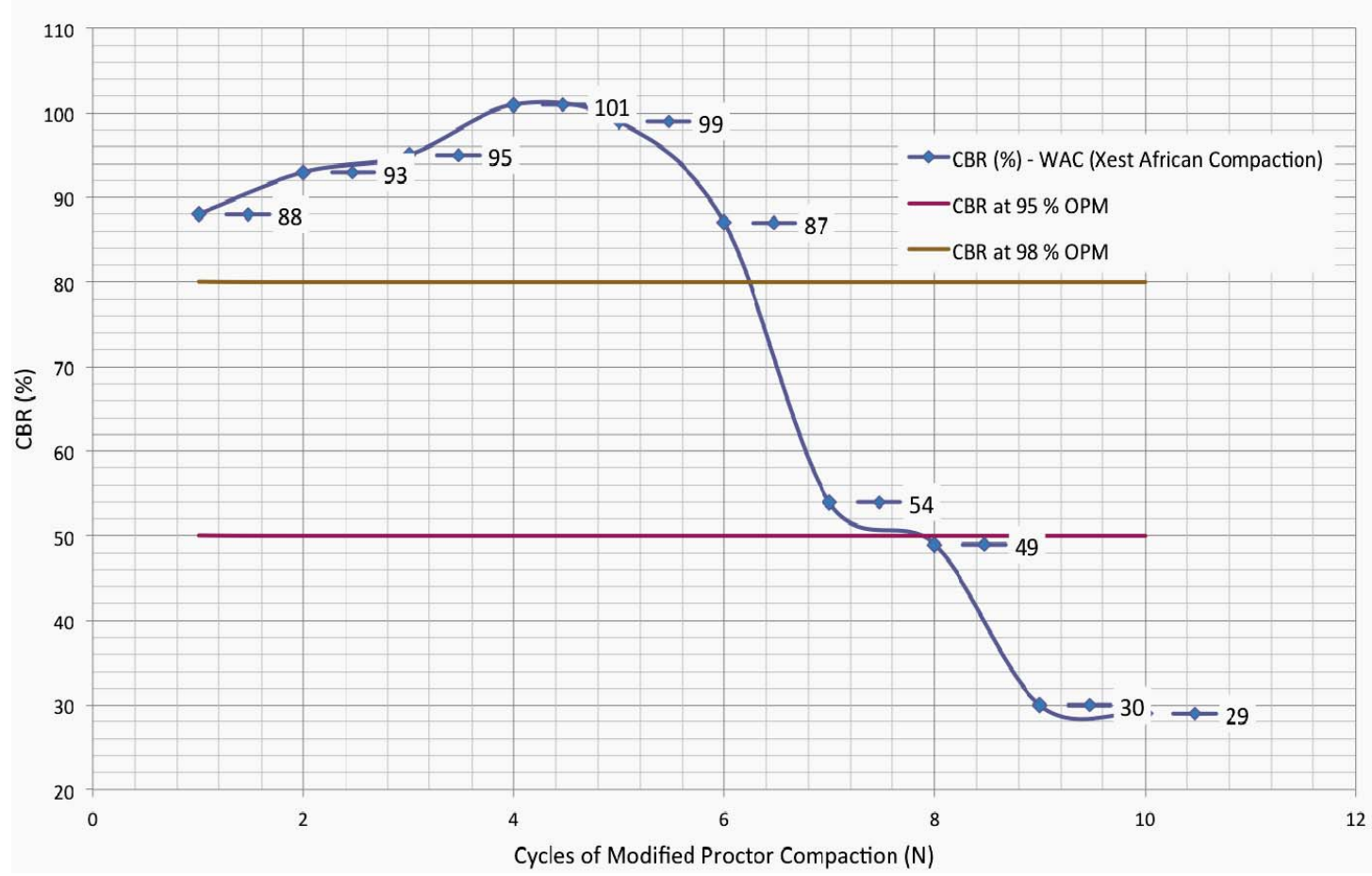

Figure 4. Comparison of CBR values with the requirements of the WAS.

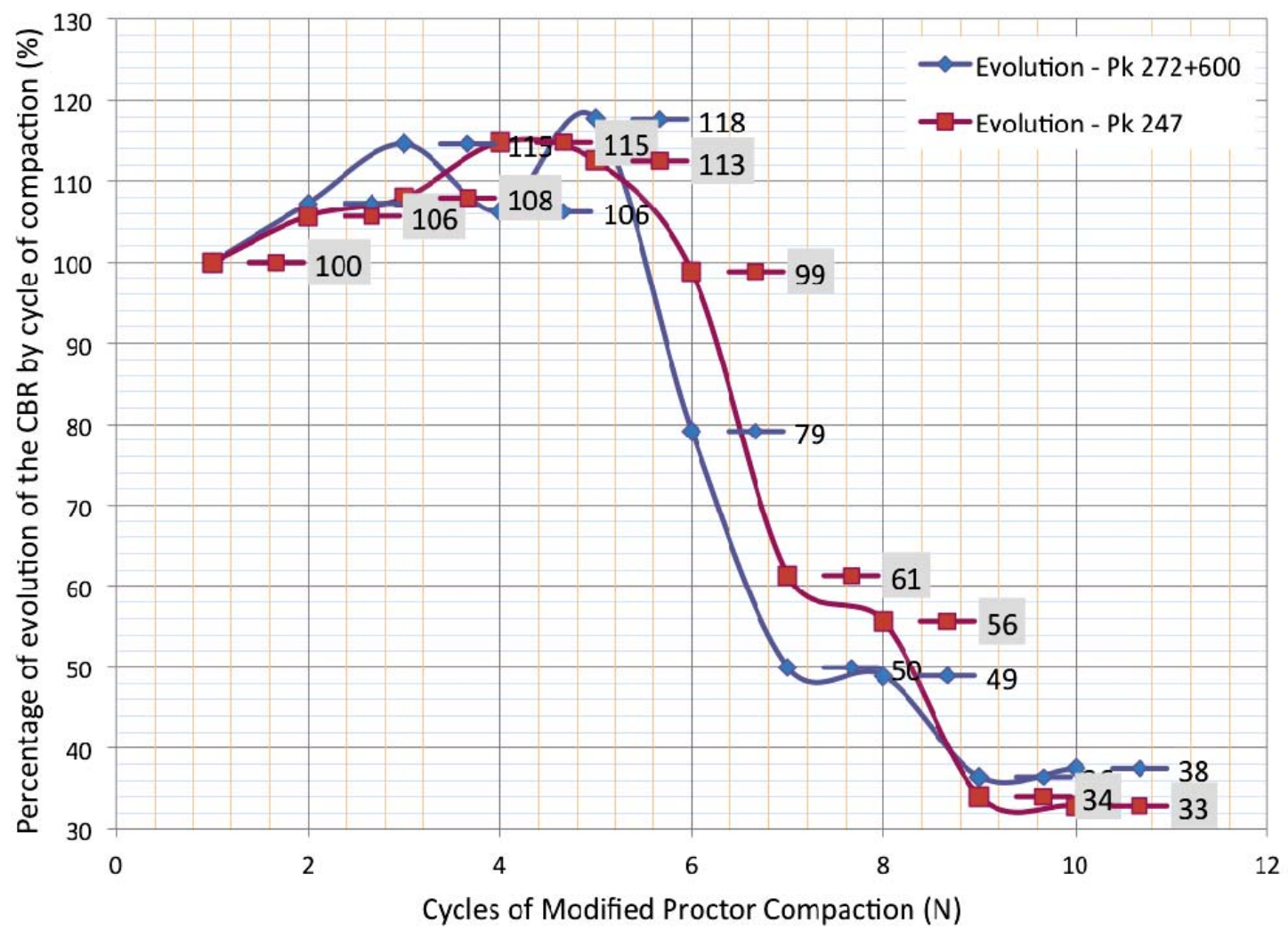

Figure 5. Percentage of evolution of the CBR values with cycles of compaction. 


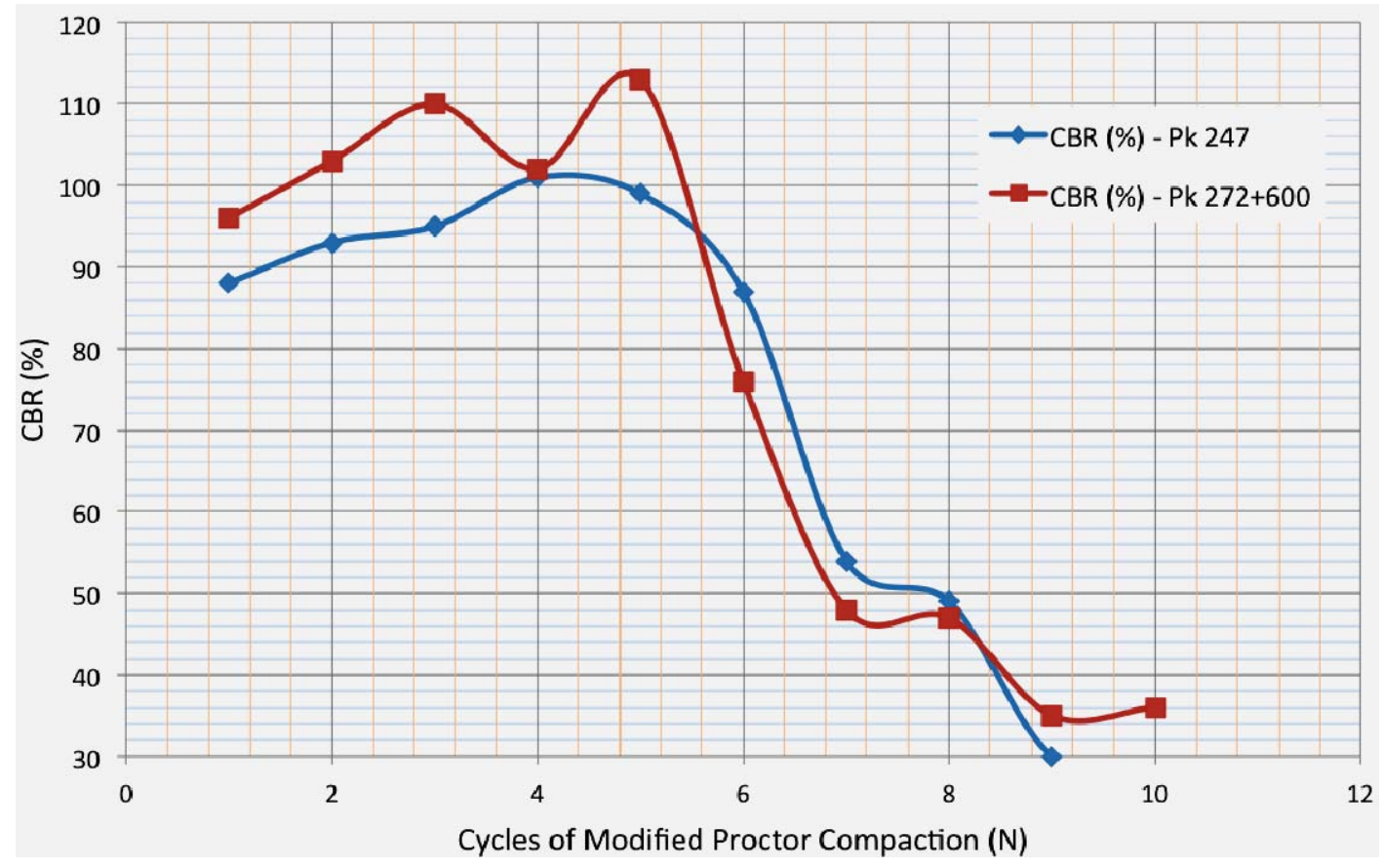

Figure 6. Evolution CBR value with cycle of compaction.

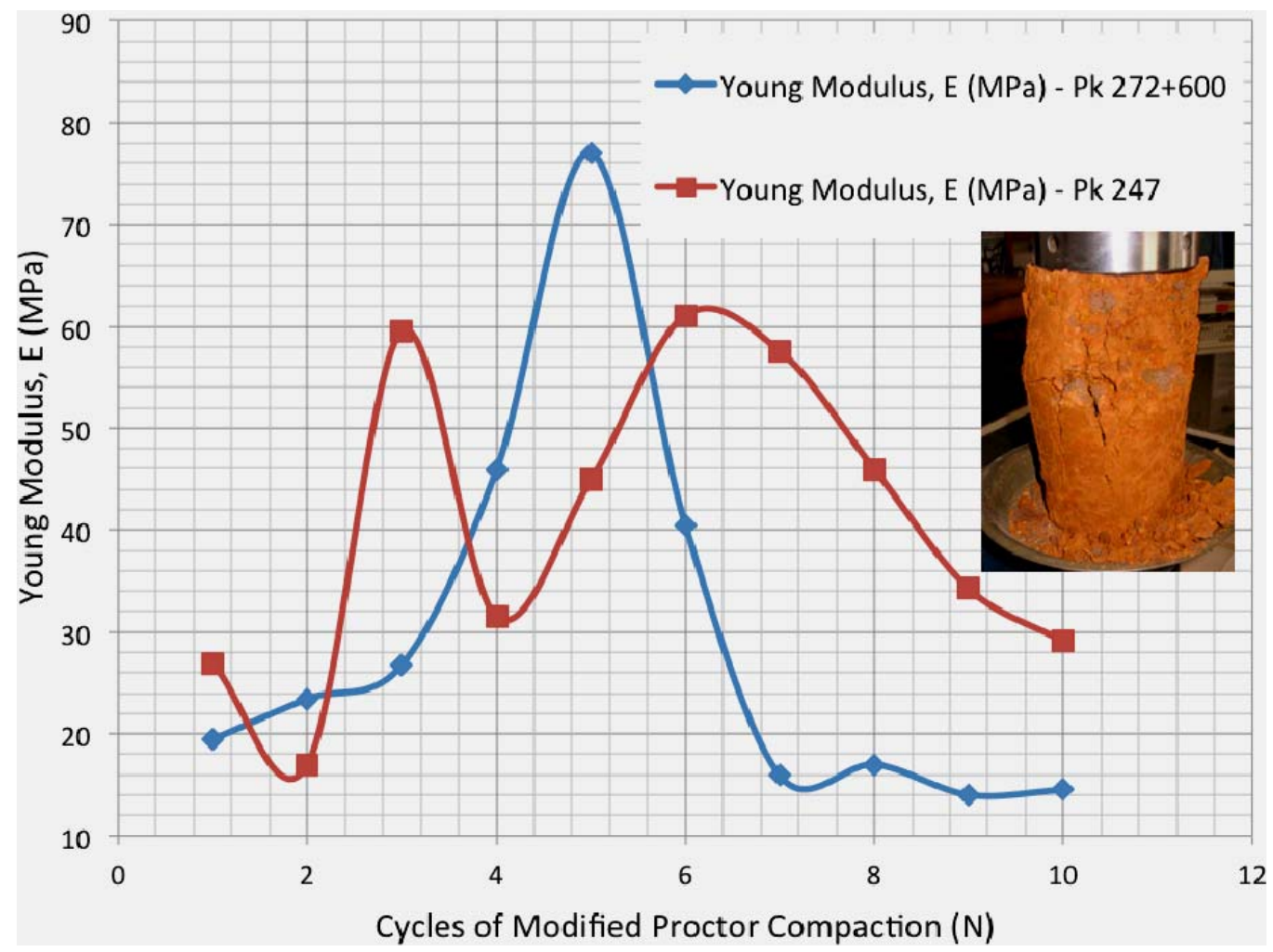

Figure 7. Evolution of the young modulus.

\subsection{Evolution of Young Moduli (E: Obtained from UCT Tests)}

Figure 7 give an illustration of the samples during the
Unconfined Compression Test to determine de modulus of elasticity of materials used in this study. Figure 8 also shows quite clearly the mechanical behavior of gravel lateritic soils under cyclic loading. We observe that the 
shear strength follows the same trend as that observed with CBR values.

During the first cycles, the moduli of elasticity increase significantly from 17 to $61 \mathrm{MPa}$ (for material of $\mathrm{Pk} 247$ ) and from 19 to $77 \mathrm{MPa}$ (for material of Pk 272). After these first cycles, moduli begin to fall significantly towards lower values. This has the same meaning as for the CBR that is soils become stiffer at the beginning of the compaction cycles and after the behavior changes completely for the last cycles. This mechanical behavior is well known in the literature and often explains the stabilization and the improvement of gravel lateritic soils with lime, cement or fly ash, for the sole purpose of increasing their shear strength under traffic loading without getting materials to behave as a slab.

$\mathrm{CBR}$ is an important parameter in pavement design if unconfined compression tests cannot be performed to get the Young's moduli. In this case, it is often used in empirical correlations to obtain static and dynamic moduli. Thus, for most tropical countries and according to textbook used as reference, the following correlations are used:

$$
\begin{array}{ll}
\checkmark & E_{\text {static }}=50 \times \mathrm{CBR}(\text { in bars), } \\
\checkmark & E_{\text {dynamic }}=100 \times \mathrm{CBR}(\text { in bars }) .
\end{array}
$$

Although often used, these correlations are very inaccurate but still are references today in most francophone African countries where the state of the research is still rudimentary. By using the same correlation as part of this project, we get of course the same trend as for the CBR that is an increase of modulus towards a peak value at the first cycles and then the CBR decreases beyond. This implies that the modulus used for the initial design $\left(E_{0}\right)$ decreases due to increase in traffic on the road.

\subsection{Conclusions}

Taking into account the fact that the measured values of CBR and likewise those of the moduli decrease significantly after several cycles of compaction, we may well conclude that thickness of the pavement during its life will also differ significantly from the initial designed thickness. The immediate conclusion to this is that:

- The design life of the pavement is significantly reduced and lead to premature ruin of the structure,

- Initial thicknesses should be higher if the designer was well aware of these behaviors.

\section{Correlation Between Energy of Compaction and Energy of Traffic}

\subsection{Energy of Compaction}

The energy of compaction is given by:

$$
E_{C}=\frac{N \times m \times g \times h}{V_{m}}
$$

$N$ : number of blows; $m$ : mass of the hammer; $g$ : acceleration due to gravity; $h$ : height of drop of the hammer and Vm: volume of the Proctor or CBR mold.

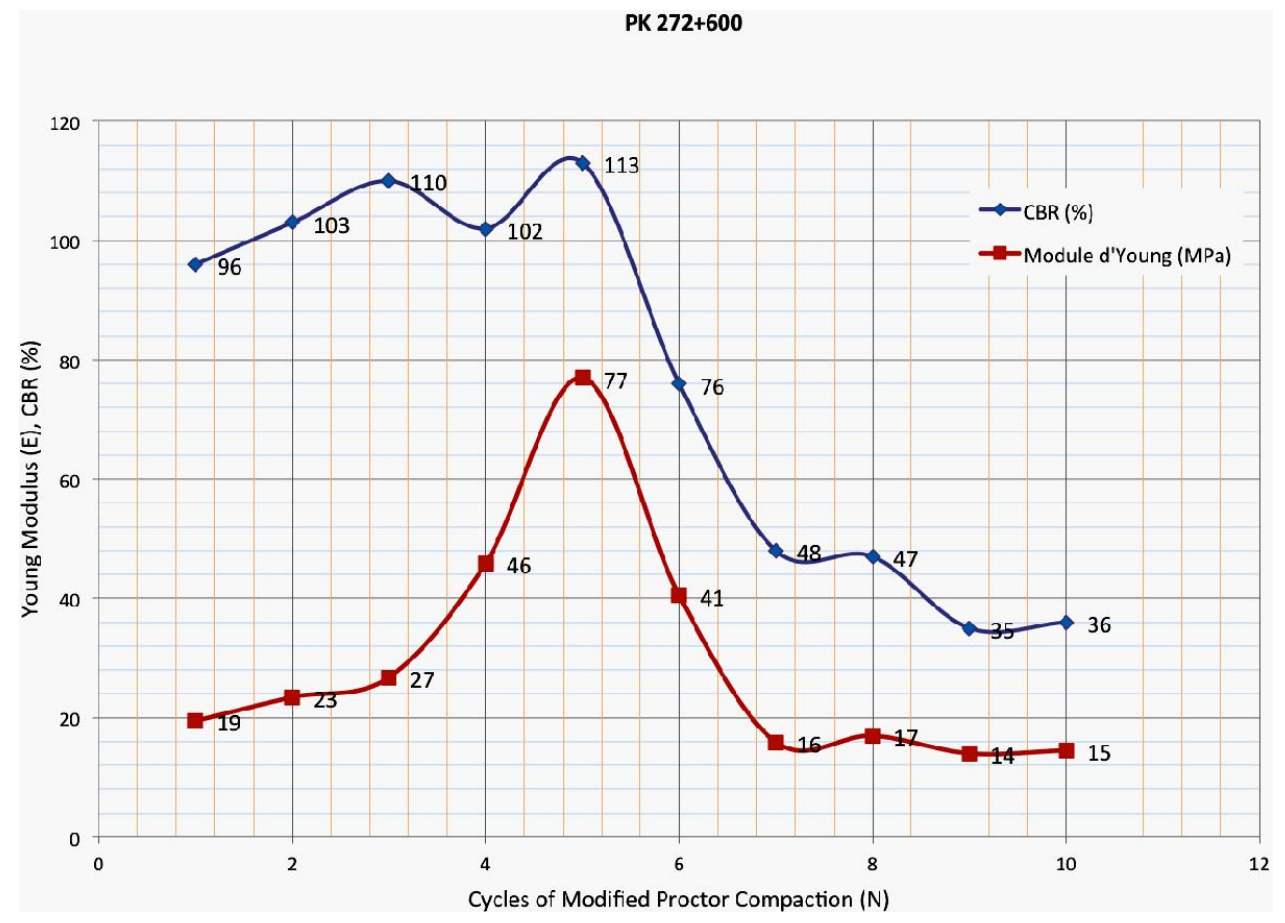

Figure 8. Evolution of design parameters (young's modulus and CBR). 


\subsection{Energy Due to Traffic}

By analogy with the energy of compaction (Table 4), the energy of traffic can be expressed as below:

$$
E_{t}=\frac{K \times g \times h}{V}
$$

$K$ is then defined by:

$$
K=Q \times T J M
$$

$Q$ is the standard axle load converted to $\mathrm{kg}$,

$G$ is the acceleration due to gravity.

$h(\mathrm{~m})$ is the thickness of the pavement, $V=h \times \pi r^{2}$ is the volume of materials involved under the standard axle (in $\mathrm{m}^{3}$ ).

After simplification $E_{t}$ becomes:

$$
E_{t}=\frac{Q \times T J M \times h}{V}
$$

So in that relationship, the only variable is TJM and the energies of traffic are determined for $\mathrm{TC}_{0}, \mathrm{TC}_{1}, \mathrm{TC}_{2}$, $\mathrm{TC}_{3}, \mathrm{TC}_{4}, \mathrm{TC}_{5}$ (Table 5 and Figure 9).

For given values of $\mathrm{x}$ and $\mathrm{y}$, we can directly calculate the TJM by the equation below:

$$
T J M=\frac{y \times \log _{10} y \times S}{Q \times g}
$$

The corresponding energy of compaction is expressed as:

$$
E_{C}=\frac{y \times \log _{10} x \times S^{\prime}}{V_{m}}
$$

For four given values of $\mathrm{x}\left(\mathrm{x}_{1}=2, \mathrm{x}_{2}=5, \mathrm{x}_{3}=8, \mathrm{x}_{4}=\right.$ $10)$, we identify the values of the corresponding ordinates for the two energies $\left(E_{t}\right.$ et $\left.E_{c}\right)$. Applying the above equations, we obtain the values of TJM and $E_{c}$ given in the table below (Table 6). $k_{t}$ and $k_{c}$ are calculated; the objective is to relate them in a relationship in order to achieve the correlation.

Let:

- $k t(1)=5.4, k t(2)=12.6$ et $k t(3)=19.2$ progression factors of Et,

- $k c(1)=23, k c(2)=50 ; k c(3)=66$ progression factors of the energy of compaction.

These ratios are calculated as below:

$$
\frac{K_{C}(1)}{K_{t}(1)}=\frac{K_{C}(2)}{K_{t}(2)}=\frac{K_{C}(3)}{K_{t}(3)}
$$

$K_{C}=4 k_{t}$, let

- $\mathrm{TJM}_{0}=10$ and TJMi $(i=1,2,3 \ldots n)$

- $E_{0}=8761,5$

Table 4. Summary of the parameter of the curve $E_{c}$.

\begin{tabular}{ccccccccccc}
\hline Cycles & $\mathbf{1}$ & $\mathbf{2}$ & $\mathbf{3}$ & $\mathbf{4}$ & $\mathbf{5}$ & $\mathbf{6}$ & $\mathbf{7}$ & $\mathbf{8}$ & $\mathbf{9}$ & $\mathbf{1 0}$ \\
\hline $\mathbf{N}$ & 275 & 550 & 825 & 1100 & 1375 & 1650 & 1925 & 2200 & 2475 & 2750 \\
$\mathbf{E}_{\mathbf{n}}(\mathbf{K J})$ & 2635 & 5276 & 7904 & 10,539 & 13,174 & 15,809 & 18,443 & 21,078 & 23,713 & 26,348 \\
$\mathbf{p}$ & 1 & 2 & 3 & 4 & 5 & 6 & 7 & 8 & 9 & 10 \\
\hline
\end{tabular}

Table 5. Summary of the parameters for drawing the curve $E_{t}$.

\begin{tabular}{ccccccc}
\hline Classes $\boldsymbol{T C \boldsymbol { C }}$ & $\boldsymbol{T C}_{\mathbf{0}}$ & $\boldsymbol{T C}_{\mathbf{1}}$ & $\boldsymbol{T C}_{\mathbf{2}}$ & $\boldsymbol{T C}_{\mathbf{3}}$ & $\boldsymbol{T C}_{\mathbf{4}}$ & $\boldsymbol{T C}_{\mathbf{5}}$ \\
\hline TJM (in heavy trucks) & 2 & 14 & 27 & 68 & 164 & 342 \\
$\mathbf{E}_{\mathbf{t}}(\mathbf{k J})$ & 51,908 & 363,354 & 700,754 & $1,764,862$ & $4,256,431$ & $8,876,217$ \\
Progression factor & 1 & 7 & 13.7 & 34 & 82 & 171 \\
\hline
\end{tabular}

Table 6. Increase in the number of heavy load vehicles and energy of compaction.

\begin{tabular}{ccccc}
\hline $\boldsymbol{T J} \boldsymbol{M}$ & 10 & 54 & 126 & 192 \\
\hline $\mathbf{k}_{\mathbf{t}}$ & 1 & 5.4 & 12.6 & 19.2 \\
$\mathbf{E c}(\mathbf{k J})$ & 8761 & 203,435 & 438,073 & 639,587 \\
$\mathbf{k}_{\mathbf{c}}$ & 1 & 23 & 50 & 73 \\
\hline
\end{tabular}




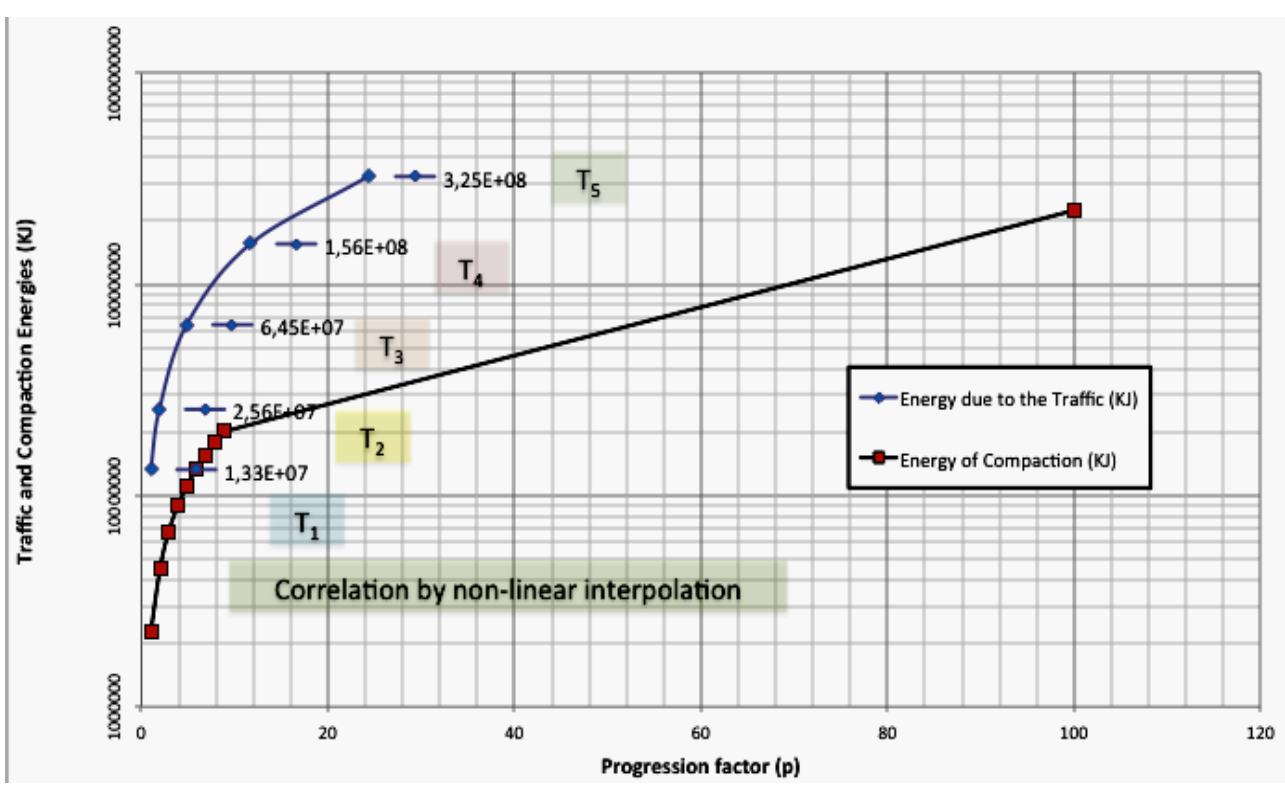

Figure 9. Curves of traffic energy and compaction energy vs progression factor.

We can write :

$$
\frac{E_{C}(i)}{E_{0}}=K_{C}=4 K t=4 \cdot \frac{T J M_{i}}{T J M_{0}}
$$

Hence,

$$
E_{C}(i)=\frac{4 E_{0}}{T J M_{0}} \cdot T J M_{i}
$$

In this formula, the energy is expressed in $k_{J}$. The formula reflects a geometric series with a common ratio expressed as below:

$$
q=\frac{4 E_{0}}{10}
$$

This result allows the designer to assume the desired traffic and then deduce the corresponding energy of compaction.

\subsection{Conclusions}

We note well that the multi-cyclic compaction simulate exactly the effect of traffic loading. In this sense, observe that increase in traffic can be simulated by an increase in the compacting cycle. At the end of compaction, the traffic reaches very high level $\left(T_{4}\right.$ to $\left.T_{5}\right)$.

\section{Conclusions}

Results show clearly that under multi-cyclic compaction, gravel lateritic soils generate fine particles, which increase their plasticity and drop their CBR value. Similarly, it is clearly shown that multi-cyclic compaction simulates well the effect of traffic by allowing reaching its expected level, which is highest traffic level at the end of the cyclic compaction.

\section{Acknowledgements}

The authors would like to acknowledge again the Entreprise Jean Lefebvre sa for their guidance and valuable input in this research project. The lateritic soils from Burkina Faso (from Boromo to Bobo Dioulasso) were collected by the help of the Entreprise Razel and sended to us by the Razel's Team of Bamoko (Mali). By this, we thank so much all of them for their ability of making the in situ samplings as well as we desire for the laboratory's tests. The large amount of materials used for this work has made the L2M laboratory's technicians as busy as they never be, the authors would like to thank them for their important contributions.

\section{References}

[1] A. Remillon, "Les recherches Routières Entreprises en Afrique D'expression Française, Application à la Conception et au Renforcement des Chaussées économiques," ITBTP, 1967.

[2] M. D. Gidigasu, "Laterite Soil Engineering-Pedogenesis and Engineering Principles," Elsevier Scientific Publishing Company, Amsterdam, 1976.

[3] T. Aashto, "Standard Method of Test for Moisture- Density Relations of Soils Using a 2.5-kg (5.5-lb) Rammer and a 305-mm (12-in.) Drop. In Standard Specifications for Transportation Materials and Methods of Sampling and Testing," American Association of State Highway 
and Transportation Officials (AASHTO), Washington DC, 1999.

[4] T. Aashto, "Standard Method of Test for the California Bearing Ratio," In Standard Specifications for Transportation Materials and Methods of Sampling and Testing, American Association of State Highway and Transportation Officials (AASHTO), Washington DC, 1993.

[5] H. R. Sreekantiah, "Laterites and Lateritic Soils of West Coast in India," Southeast Asian Geotechnical Conference, Bangkok, Vol. 1, 27 December 1987, pp. 159-170.

[6] A. Sridhan, "General Report: Engineering Properties of Tropical Soils," International Conference on Geomechn in Tropical Soils, Singapore, 12 December 1988.

[7] G. Sweere, P. Galjaard and T. Tjong, "Engineering Behaviour of Laterites in Road Constructions," International Conference on Geomechn in Tropical Soils, Singapore, Vol. 1, 1988, pp. 421-427.

[8] B. A. Vallerga, et al., "Engineering Study of Laterites and Lateritic Soils in Connection with Construction of Road, Highways and Airfields," Country Report, AID/CSD1810, 1969, p. 165 and appendices.

[9] L. W. Ackroyd, "Engineering Classification of Some Western Nigerian Soils and Their Qualities in Road Building," Road Research Laboratory, British, 1959.

[10] M. Fall, "Caractérisation et Identification mé- canique de Trois Graveleux Latéritiques du Sénégal Occidental: Application au domaine routier," Thèse de Doctorat de l'INPL en Génie Civil et Minier de l'INPL-Nancy France, 1993, p. 277.

[11] Secrétariat d'Etat aux Affaires Etrangères - CEBTPBCEOM (1984) - Guide pratique de dimensionnement des chaussées dans les pays tropicaux, CEBTP ; 2 ème édition: tome 1: Politique et économie routière ; 2 ème édition, 1991; tome 2: Etudes techniques et construction ; 2 ème édition, 1991; tome 3: Entretien et gestion des routes ; 2 ème édition, 1991. 